\title{
A interação social na lista de discussão ABRH-Gestão e o estabelecimento de uma comunidade virtual imaginada ${ }^{1}$
}

\author{
Cynthia Harumy Watanabe Corrêa ${ }^{2}$ \\ PUC-RS \\ cynthiahwc@yahoo.com.br
}

\begin{abstract}
Resumo: $O$ objetivo do estudo foi investigar o processo de interação social em uma lista de discussão formada por acadêmicos $e$ pesquisadores da área de recursos hídricos, visando identificar o grupo reunido na lista da Associação Brasileira de Recursos Hídricos (ABRH-Gestão) como uma comunidade virtual. A dinâmica de interação entre os membros da lista de discussão foi observada a partir do método netnográfico, de enfoque qualitativo, durante o período de janeiro a junho de 2004. Como resultado, foi verificado que pessoas geograficamente dispersas e que atuam em diferentes atividades profissionais mantêm a lista ABRH-Gestão em plena efervescência há mais de cinco anos, convivendo em meio a diálogos $e$ debates em uma comunidade virtual imaginada.
\end{abstract}

Résumé: L'objet de l'étude fut d'investigner l'intération sociale dans une liste de discussion formée par académiciens et chercheurs dans l'aire des ressources hydriques, ayant en vue d'identifier le groupe réuni dans l'Associação Brasileira de Recursos Hídricos (ABRHGestão) comme une communauté virtuelle. La dynamique de l'intération entre les membres de la liste de discussion fut observée à partir de la méthode nétnographique sous une optique qualitative, pendant la période janvier/juin 2004. Comme résultat, il fut vérifié que des personnes géographiquement éloignées et qui exercent différentes activités professionneles maintiennent la liste ABRHGestão en plein fonctionnement depuis plus de cinq ans participant de dialogues et débats au sein d'une communauté virtuelle imaginée.

Summary: The objective of this study was investigate the social interaction among academics and researchers, participating in a discussion group on water resources, to evaluate the scientific community associated to the Associação Brasileira de Recursos

\footnotetext{
${ }^{1}$ Fundamentado na dissertação "Interação social da comunidade científica no ciberespaço: estudo da lista ABRH-Gestão”, defendida junto ao Programa de Pós-Graduação em Comunicação e Informação da Universidade Federal do Rio Grande do Sul/UFRGS, Porto Alegre/RS, em 21/01/05.

${ }^{2}$ Doutoranda em Comunicação Social pela Pontifícia Universidade Católica do Rio Grande do Sul/PUCRS e bolsista do Conselho Nacional de Desenvolvimento Científico e Tecnológico/CNPq.
} 
Hídricos (ABRH-Gestão) as a virtual community. Social interaction among the discussion group members was qualitatively analyzed through netnographic method, from January to June 2004 and by participation in the group. As a result, it was verified that the ABRHGestão is a geographically spread group which has been active for over five years, involving people working in different fields, who interact in discussions and debates in an imaginary virtual community.

Resumen: El objetivo de este estudio fue analizar el proceso de interacción social en una lista de discusión electrónica constituida por académicos y investigadores centrados en el tema de los recursos hídricos, para identificar la lista vinculada a la "Associação Brasileira de Recursos Hídricos" (ABRH-Gestão) como una comunidad virtual. La observación de la dinámica de la interacción entre los miembros de la lista fue realizada a través del método netnográfico, durante el período de Enero a Junio de 2004. Como resultado, fue comprobado que personas geográficamente dispersas y con diferentes actuaciones profesionales mantienen la lista en plena efervescencia desde hace cinco años, conviviendo entre diálogos y debates en una comunidad virtual imaginable.

Palavras-chave: Comunidade científica brasileira. Comunidade virtual. Netnografia.

Mots-clé: Communauté scientifique brésilienne. Communauté virtuelle. Nétnographie.

Keywords: Brazilian scientific community. Virtual community. Netnography.

Palabras clave: Comunidad científica brasileña. Comunidad virtual. Netnográfia. 


\section{Introdução}

O aperfeiçoamento e o uso das Tecnologias de Informação e de Comunicação (TICs), da Comunicação Mediada por Computador (CMC) e da rede Internet promoveram modificações na estrutura organizacional de sistemas sociais, políticos e econômicos em escala planetária. De um modo geral, o uso crescente da Internet resultou em um rearranjo da organização social, tornando possível o estabelecimento de relações sociais por meio de redes de computadores de alcance mundial, caracterizando a sociedade em rede e o predomínio de uma cibercultura.

Entre os agrupamentos sociais originados no ciberespaço, destacam-se as comunidades virtuais (Rheingold, 1998; Lemos, 2002a, 2002b; Jones, 1997) constituídas a partir da identificação de afinidades e de interesses comuns, pessoais e profissionais. Nesse contexto, aparecem grupos voltados para a área acadêmica e de pesquisa, sendo que a comunidade científica foi inicialmente beneficiada com o uso da CMC e da própria Internet quando a rede dava os primeiros passos por volta de 1969 e recebia o nome de Advanced Research and Projects Agency (ARPANET).

Estudos sobre a avaliação dos impactos das TICs na comunidade científica brasileira (Costa, 2000; Pinheiro, 2003; Souza, 2003) comprovam que as atividades de ensino e pesquisa passaram por modificações de hábitos e costumes através de novas formas de comunicar e de produzir conhecimento em ambientes virtuais. Além disso, sabe-se que o fazer ciência está relacionado diretamente à ação de comunicar, pois é somente por meio do intercâmbio de informações entre os pares que se pode dar continuidade a projetos de pesquisa.

Por outro lado, na era da informação, era do conhecimento ou da sociedade em rede (Castells, 1999, 2003), a informação é vista como objeto mais valioso. Deste ponto de vista, chama atenção verificar de que forma a comunidade científica brasileira, que atua com a produção de conhecimento, 
utiliza as tecnologias de comunicação da Internet, em especial uma lista de discussão. Essa abordagem ainda colabora para se manter em estado de alerta perante as tecnologias de comunicação, afastando uma visão otimista e mesmo de endeusamento do aparato tecnológico que é comum na sociedade contemporânea. De acordo com Wolton (2003), a ênfase deve ser dada ao fenômeno da comunicação que é uma característica humana, uma vez que as pessoas precisam interagir para viver em sociedade. Nesse sentido, o autor considera fundamental investigar a comunicação em suas dimensões técnica, cultural e social, e confrontá-las com uma visão de conjunto da sociedade.

Partindo do pressuposto que o processo de comunicação de acadêmicos e cientistas foi e está sendo alterado também pelo desenvolvimento e apropriação de tecnologias de comunicação, como a Internet, apresenta-se como objetivo geral da pesquisa analisar o grupo reunido na lista de discussão sobre Gestão de recursos hídricos da Associação Brasileira de Recursos Hídricos (ABRH-Gestão) enquanto uma comunidade virtual científica. Entre os objetivos específicos destacam-se: observar a estrutura do processo comunicacional na lista; examinar a linguagem e os recursos utilizados pelos membros da ABRH-Gestão; identificar na lista características de uma comunidade virtual; analisar a interação social e o compartilhamento de saberes na lista; e examinar o papel do moderador.

A escolha da lista sobre Gestão de recursos hídricos deve-se ao fato do tema ser alvo de debates sobre a conservação dos ecossistemas de água doce para atender às demandas da sociedade em nível global. No caso brasileiro, o assunto é visto como relevante porque o país concentra a maior quantidade de água doce do planeta. O Brasil detém ainda a maior área úmida continental do mundo (Pantanal), as mais extensas florestas alagadas (Amazônia) e uma fauna aquática rica. 


\section{As listas de discussão}

A Internet, enquanto meio de comunicação, apresenta diversas tecnologias que podem proporcionar uma maior integração, colaboração mútua, cooperação e troca de conhecimento e experiência entre os internautas. Cada ferramenta apresenta certas possibilidades e diferentes usos, sendo classificadas em relação à dimensão tempo em síncronas ou assíncronas.

Os meios síncronos exigem a presença simultânea de dois ou mais internautas para haver comunicação e a mensagem enviada é recebida imediatamente, como as salas de bate-papo ou chat (Internet Relay Chat), os jogos em ambientes virtuais e os sistemas de troca de mensagem instantânea (instant messenger). Nos meios assíncronos, os participantes não precisam estar simultaneamente conectados para que a comunicação ocorra, é o caso do correio eletrônico e da lista de discussão, que funciona via troca de mensagens assíncronas entre participantes (Sá, 2002).

As listas de discussão surgem na década de 70 como um sistema de comunicação adaptado para a comunicação coletiva, todos-todos, baseado na cooperação dos participantes e no intercâmbio de conhecimentos. Os integrantes de listas de discussão não fazem uso apenas do correio eletrônico para enviar mensagens aos demais participantes do grupo, usam outros recursos e tecnologias que podem ser síncronos ou assíncronos. É comum a transmissão de arquivos contendo texto, imagem, som, vídeo e o contato via sistema de mensagem instantânea e salas de bate-papo. A palavra escrita é predominante nesse sistema de comunicação e a estruturação do discurso é apresentada de modo linear (Fuks; Gerosa; Pimentel, 2003).

Assim, o êxito de uma lista de discussão depende exclusivamente da participação dos membros para que seja vista como um lugar de intercâmbio coletivo, aberto a todos os interessados a compartilhar saberes, conhecimentos e preocupações em comum. Segundo Sá (2002), o caráter 
público destas listas se estabelece a partir do acesso às mensagens que são recebidas por todos os participantes, criando um fórum de debate permanente para além das eventuais chegadas e partidas de um ou outro membro, onde cada um participa como pode ou deseja, de acordo com o interesse e a própria personalidade.

As listas de discussão começam a se destacar entre os recursos de comunicação mais utilizados pela comunidade científica no país, só ficando atrás do correio eletrônico, de acordo com pesquisa de Pinheiro (2003). Tanto que uma busca preliminar no sistema Yahoo! Brasil Grupos, que provê o suporte a listas de discussão, revela a existência de uma grande quantidade de listas enfatizando diferentes áreas do conhecimento. Muitas listas registram uma baixa participação em volume de mensagens e em número de integrantes, porém, isto se explica pelo tipo de assunto ressaltado e por, normalmente, formarem grupos de acesso fechado.

A lista ABRH-Gestão está classificada na categoria de Meio Ambiente e é mantida em atividade há mais de cinco anos por cerca de 650 participantes estudantes, professores, pesquisadores e profissionais da área, que também são representantes da comunidade científica brasileira. Outro aspecto importante para a seleção desta lista é o seu vínculo à Associação Brasileira de Recursos Hídricos (ABRH), o que garante a confiabilidade e a seriedade da discussão e, ao mesmo tempo, colabora para caracterizar o fazer ciência como uma prática institucionalizada.

A lista ABRH-Gestão foi criada no dia 22 de junho de 1999 e conta com participantes de diferentes localidades geográficas e de diversas instituições. A própria ABRH utiliza a lista para enviar informes em geral, mas não se trata de um meio de comunicação oficial da Associação, como é o caso da Revista Brasileira de Recursos Hídricos (RBRH), que há mais de 25 anos divulga conhecimento técnico-científico da comunidade brasileira de recursos hídricos. 
A ABRH é uma entidade que tem o objetivo de congregar pessoas físicas e jurídicas ligadas ao planejamento e à gestão dos recursos hídricos no Brasil. Por meio dos seus sócios, ela desenvolve ações de caráter técnico-científico, jurídico-institucional e social, e encaminha soluções para problemas relacionados à área de recursos hídricos, visando atender aos interesses da sociedade (Associação..., 2004).

A lista de discussão utiliza o suporte do sistema Yahoo! Brasil Grupos e está aberta à qualquer pessoa interessada na temática, ou seja, a participação não é restrita aos sócios oficiais da ABRH, que somavam 914 na época de realização da pesquisa. Desse modo, a lista selecionada para análise é uma rede social gratuita que permite a participação, ou melhor, a associação de qualquer pessoa interessada no tema, independentemente dos pontos de vista, que podem ser os mais variados e divergentes.

\section{A comunicação científica on-line}

O surgimento da Internet e a conseqüente disponibilização de variadas tecnologias de comunicação facilitaram o encontro, a organização, o intercâmbio, o debate e a visibilidade de grupos, agregações eletrônicas ou comunidades virtuais com interesses particulares. Nesse cenário, distingue-se a participação na rede de grupos pertencentes à área acadêmica e de ciência e tecnologia, que foram os primeiros a se beneficiar com o desenvolvimento das TICs em todo o mundo. Castells $(1999,2003)$ ressalta que a própria Internet originou-se a partir de uma rede internacional de cientistas e técnicos que compartilhavam e desenvolviam tecnologias em cooperação, inclusive quando a rede fazia parte do Departamento de Defesa dos Estados Unidos.

Como se observa, o envolvimento do mundo da ciência com a cibercultura vem de longa data. Segundo Meadows (1999), o computador já era empregado no processamento de informações na década de 1960 e sua evolução o transformaria em ferramenta cada vez mais eficaz para a 
comunicação científica. Para Russell (2000), não há dúvidas que o aperfeiçoamento e a disseminação da tecnologia da informação das últimas décadas revolucionaram as formas dos cientistas se comunicarem, assim como o crescimento exponencial do uso das redes eletrônicas abriu novas possibilidades para a divulgação de informações sobre pesquisas.

Além disso, a iniciativa de promover a comunicação também está de acordo com uma das características principais da filosofia do método científico: dar publicidade a experimentos e achados de pesquisadores; permitindo a ampla troca de informações entre os pares e acelerando o avanço da ciência. Em outras palavras, o avanço do processo de investigação científica depende sobremaneira da circulação de informações entre os pares, pois a teoria proposta por um pesquisador deve ser testada e avaliada criticamente por outros cientistas para poder ter sua validade reconhecida.

Nesse aspecto é que Meadows (1999) afirma que a comunicação está situada no próprio coração da ciência, existindo uma necessidade intrínseca por parte do cientista de manter um intercâmbio e de trocar informações para dar continuidade a projetos de pesquisa. $\mathrm{O}$ conhecimento necessita de modo conjunto e interdependente de experiência e de experiências, de confrontos, de diálogos, de debates, de discussões, de acordos e conflitos para lutar contra os seus inimigos internos e externos. Na concepção de Morin (1999), foi nesse processo dialógico que se consolidou o conhecimento científico, o qual por meio de uma regra permite o desenvolvimento da prática, como observações e experiências; da comunicação, ou seja, troca de informação, divulgação de descobertas e dos meios de investigação, debates e discussões; e da reflexão, de ordem teórica e crítica.

Um estudo realizado por Costa (2000) sobre a utilização das redes de computadores por economistas e sociólogos brasileiros e ingleses indicou que a facilidade em contatar colegas via redes eletrônicas globais tornou a interação nesse nível mais real. Houve um aumento na produção de pesquisas 
em parceria e na publicação de trabalhos em co-autoria com pessoas geograficamente distantes e que, em muitos casos, jamais se encontram. Portanto, um dos principais impactos do uso de computadores e redes eletrônicas no grupo observado foi a ampliação da dinâmica nas interações (com os pares - interações sociais - e com os recursos de informação) dentro das comunidades científicas.

Dessa forma, a Internet une o mundo científico à medida que pode colaborar para diminuir as disparidades de acesso aos resultados de pesquisas divulgados a todo instante em vários países, agilizando e otimizando o trabalho de cientistas que atuam em regiões concebidas como periferias em se tratando de iniciativa científica. A comunicação via redes de computação ignora significativamente a barreira espacial e temporal que tanto tornava lenta a circulação de informações sobre ciência, além da capacidade de armazenamento de dados que está disponível em formato digital, podendo abranger arquivos contendo texto, imagem e som.

\begin{abstract}
Um livro contém uma quantidade limitada de informação que só pode ser extraída por um número limitado de maneiras. A informação eletrônica equivalente pode ser ligada a uma quantidade virtualmente ilimitada de informação adicional, a qual o usuário pode ter acesso de várias maneiras, de acordo com o seu desejo. Assim, ser "alfabetizado em computador" implica maior leque de atividades do que é necessário para ser alfabetizado. (MEADOWS, 2000, p. 25).
\end{abstract}

De acordo com o autor, considera-se a comunidade científica, especialmente no caso brasileiro, um dos grupos mais representativos da chamada sociedade da informação. Trata-se de um grupo que apresenta competência educacional para selecionar informações de qualidade na Internet e para manusear adequadamente as diferentes possibilidades oferecidas por esta rede que, enquanto meio de comunicação, pode proporcionar uma maior integração, cooperação e troca de conhecimento e experiência entre os internautas. Logo, a utilização da Internet pela 
comunidade científica brasileira possibilita a consolidação de uma cibercultura científica no Brasil, caracterizada pela apropriação das tecnologias comunicacionais na prática de ensino e pesquisa de estudantes, professores, pesquisadores e cientistas espalhados no país.

\title{
O processo de formação de comunidades virtuais
}

Um fato curioso desse período é que embora a sociedade esteja conectada mundialmente via redes de computador, o indivíduo continua sentindo necessidade de se integrar a grupos com os quais tenha alguma identificação. Para desfazer o paradoxo subentendido, recorre-se a Wolton (2003) para quem não há nada mais perigoso do que ver na presença das novas tecnologias a condição para a aproximação entre os homens. Apesar de todas suas performances, as novas mídias não são capazes de promover uma melhor comunicação humana ou social. Por esse viés, o autor esclarece que se as tecnologias são o elemento mais visível da comunicação, o que merece ser observado é o modelo cultural vigente na sociedade a partir do contato com estas técnicas.

\begin{abstract}
Dito de outra forma, de uma tecnologia de comunicação, o essencial é menos a performance da ferramenta do que a ligação existente entre esta técnica, o modelo cultural de relacionamento dos indivíduos e o projeto para o qual esta tecnologia está destinada. A técnica não é o suficiente para mudar a comunicação na sociedade, e é por esta razão que numerosas "revoluções das tecnologias de comunicação" não tiveram o impacto esperado, simplesmente porque não estavam em sintonia com nenhum movimento mais geral relativo à evolução do modelo cultural de comunicação. (WOLTON, 2003, p. 32-33).
\end{abstract}

Tendo como princípio que a comunicação é uma característica humana, pois as pessoas precisam interagir para viver em sociedade, e que as tecnologias não representam a condição básica para que um comportamento natural do ser humano se manifeste, procura-se compreender os fenômenos 
sociais com base no modelo cultural em vigor. Desse ponto de vista, analisa-se a tendência das pessoas de se reunirem em grupos sociais visando compartilhar interesses em comum através da formação de comunidades virtuais como uma estratégia do indivíduo inserido em uma sociedade em rede de se fazer reconhecer por meio de uma ou várias identidades.

A busca de novos traços de identidade na cibercultura contemporânea, a partir da agregação comunitária virtual, reflete os efeitos da globalização, os quais implicam um movimento de distanciamento da idéia sociológica clássica da sociedade como um sistema bem delimitado. Quando passa a vigorar uma perspectiva apoiada na forma como a vida social está ordenada ao longo do tempo e do espaço, que desencadeia um processo de enfraquecimento e fragmentação das identidades, particularmente da identidade nacional (Hall, 2001). Nesse contexto, as barreiras espaciais, temporais e geográficas já não são significativas, quando as redes globais de intercâmbios conectam e desconectam indivíduos, grupos, regiões e até países sob os efeitos globalizantes provenientes da pós-modernidade.

A idéia de pós-modernidade aparece na segunda metade do século XX com o advento da sociedade de consumo e dos mass media, associados à queda das grandes ideologias modernas e de idéias centrais como história, razão, progresso. Agora, os campos da política, da ciência e da tecnologia, da economia, da moral, da filosofia, da arte, da vida quotidiana, do conhecimento e da comunicação vão sofrer uma modificação radical. (LEMOS, 2002b, p. 67).

Diante desse cenário, o indivíduo desprovido de referências tradicionais sai à procura de pessoas com as quais possa compartilhar interesses em comum, ação que se repete, uma vez que é da natureza humana se relacionar socialmente. Nos últimos tempos, porém, tal prática parece ter sido intensificada com a presença das redes mundiais de computadores, que aproximam os indivíduos e possibilitam o surgimento de novas formas de 
relações sociais, entre as quais se destacam as comunidades virtuais, espécie de agrupamentos humanos constituídos no ambiente virtual (Rheingold, 1998).

Também para Hall (2001), uma das características principais da globalização sobre as identidades nacionais é a compressão espaço-tempo, isto é, a aceleração dos processos globais, fazendo com que se sinta o mundo menor e as distâncias mais curtas, quando eventos ocorridos em um lugar específico têm um impacto imediato sobre pessoas e lugares situados a uma grande distância.

\begin{abstract}
Quanto mais a vida social se torna mediada pelo mercado global de estilos, lugares e imagens, pelas viagens internacionais, pelas imagens da mídia e pelos sistemas de comunicação globalmente interligados, mais as identidades se tornam desvinculadas desalojadas - de tempos, lugares, histórias e tradições específicos e parecem "flutuar livremente". Somos confrontados por uma gama de diferentes identidades (cada qual nos fazendo apelos, ou melhor, fazendo apelos a diferentes partes de nós) dentre as quais parece possível fazer uma escolha. (HALL, 2001, p. 75).
\end{abstract}

Nesse panorama agitado e confuso, certamente a pessoa é capaz de fazer uma escolha, optar por uma determinada identidade, por um determinado papel diante de tantos outros que cabe a ela desempenhar, mas isso a cada novo instante da sua vida. Processo que se intensifica pela possibilidade de conexão mundial via redes de computadores, que tornam mais estreitas as fronteiras espaço-temporais, pois as ações são realizadas em tempo real em um ciberespaço de natureza global.

As primeiras comunidades virtuais foram criadas via redes de computadores que surgiram nos Estados Unidos antes mesmo da estruturação da Internet, por volta dos anos 7o. É o caso da rede Usenet, considerada uma das formas eletrônicas mais populares de organização social nas redes. A Usenet é hoje um sistema telemático que permite o contato entre as pessoas e 
a promoção de fóruns de conversação organizados a partir de grupos temáticos, os newsgroups.

O conceito de comunidades virtuais foi definido por Rheingold (1998) como "[...] agregações sociais que emergem na Internet quando uma quantidade significativa de pessoas promove discussões públicas em um período de tempo suficiente, com emoções suficientes, para formar teias de relações pessoais no ciberespaço"3. Lemos (2002a), por sua vez, contribui com o debate ao afirmar que nem toda forma agregadora da Internet pode receber o rótulo de comunitária, pois existem certos agrupamentos sociais em que os participantes não mantêm qualquer vínculo afetivo e/ou temporal.

De toda maneira, o ciberespaço potencializa o surgimento de comunidades virtuais e de agregações eletrônicas delineadas em torno de interesses comuns, de traços de identificação, sendo capaz de aproximar e de conectar indivíduos que talvez nunca tivessem oportunidade de se encontrar pessoalmente. Ambiente que ignora definitivamente a noção de tempo e espaço como barreiras.

É interessante observar, ainda, que no estabelecimento de comunidades no ciberespaço prevalece a noção clássica que distingue toda comunidade, a qual está ligada à idéia de um espaço de partilha, a uma sensação, a um sentimento de pertencimento, de inter-relacionamento íntimo a determinado agrupamento social (Lemos, 2002b). É o interesse em comum partilhado que transmite à comunidade o sentimento de pertencimento. Desse ponto de vista, Silva (2003) argumenta que, apesar do laço social servir de cimento à vida em sociedade, ele só se atualiza pela força de valores partilhados, de imagens reverenciadas em conjunto e de sentimentos e afetos intensificados pela comunhão. Não há laço social sem imaginário.

3 Tradução livre do texto: "Virtual communities are social aggregations that emerge from the Net when enough people carry on those public discussions long enough, with sufficient human feeling, to form webs of personal relationships in cyberspace”. (RHEINGOLD, 1998). 
No interior das comunidades virtuais, podem existir elementos como solidariedade, emoção, conflito, imaginação coletiva, identificação, comunhão, interesses comuns, interação. Também são adotadas regras de conduta denominadas de Netiqueta, havendo punição para os que desobedecerem aos valores do grupo. Para que o sentimento de comunhão se propague, é necessário que haja compartilhamento de saberes, de conhecimento, de opiniões que podem até ser contraditórias e conflitantes, que é uma forma saudável de verificar o grau de tolerância entre os membros. Ademais, a existência de idéias conflitantes pode resultar na elaboração de novos saberes a partir de debates e discussões.

No ambiente virtual, o indivíduo escolhe, elege qual comunidade quer fazer parte, sendo a principal motivação o seu interesse particular em um ou vários assuntos em que percebe uma identificação e encontra pessoas com as quais possa compartilhar idéias e promover discussões públicas, uma vez que a interação mútua ${ }^{4}$, relação recíproca que ocorre entre as pessoas que se comunicam por meio do computador, é fundamental para o estabelecimento e consolidação de comunidades virtuais (Primo, 1998).

Essa possibilidade de escolher os traços de identificação é o que basicamente diferencia a constituição de comunidades virtuais do modelo tradicional de atribuição de identidades culturais, como o caso da identidade nacional, em que todo um povo era e ainda é obrigado a aderir a determinados símbolos nacionais, como hino e bandeira, e a manter vínculos a lugares, datas comemorativas, histórias e a tradições específicas, por exemplo. Sobre a questão da identidade, Hall (2001) afirma que em decorrência do fenômeno de globalização ocorreu um afrouxamento de fortes identificações com a cultura nacional e, ao mesmo tempo, foram reforçados outros laços e lealdades culturais diferentes do nível do Estado-nação.

\footnotetext{
4 Primo (1998) distingue dois níveis de interação em ambientes virtuais: a mútua, que é fundamental para a constituição de comunidades virtuais, pois é a relação construída entre pessoas; e a interação reativa, que é pré-determinada, como o hiperlink que é reativo, só leva a um lugar, a um site específico, interação homem-máquina.
} 
Além disso, a partir da concepção de Anderson (1989, p. 14), compreende-se o conceito de nação definido como:

[...] comunidade política imaginada - e imaginada como implicitamente limitada e soberana. Ela é imaginada porque nem mesmo os membros das menores nações jamais conhecerão a maioria de seus compatriotas, nem os encontrarão, nem sequer ouvirão falar deles, embora na mente de cada um esteja viva a imagem de sua comunhão.

Para esse autor, todas as comunidades maiores que as primitivas aldeias de contato face a face ou até mesmo estas sempre foram imaginadas. A nação é imaginada como comunidade porque, ao ignorar a desigualdade e a exploração que prevalecem no interior de todas elas, a nação é sempre concebida como um companheirismo profundo e horizontal. Dessa forma, pode-se entender a identidade também como algo formado, ao longo do tempo, e não como algo que acompanha o indivíduo desde o nascimento. Existe, então, sempre algo imaginado ou fantasiado sobre sua unidade (Hall, 2001).

De fato, os conceitos de identidade cultural e de nação funcionam como recursos que visam manter o controle e reprimir as diferenças sociais, culturais, educacionais, econômicas e políticas de uma população. Há uma tentativa de padronização e homogeneização de um povo, disseminando uma idéia de união e de coesão que ignora qualquer tipo de diferença e que, portanto, não representa o cotidiano das pessoas que vivem sob o mesmo território. Ao reconhecer que a identidade é uma construção, que está constantemente sendo elaborada, Hall (2001, p. 39) sugere que se fale de "identificação":

A identidade surge não tanto da plenitude da identidade que já está dentro de nós como indivíduos, mas de uma falta de inteireza 
que é "preenchida" a partir de nosso exterior, pelas formas através das quais nós imaginamos ser vistos por outros.

Esse movimento contínuo de elaboração de identidade a partir da identificação e do reconhecimento do indivíduo pelo imaginário dos outros também se manifesta no processo de constituição de comunidades virtuais. Dessa maneira, acredita-se que a formação de comunidades virtuais, entendidas enquanto comunidades imaginadas (Anderson, 1989) e constituídas por sentimentos como afeto, vem ajudando a suprir esta necessidade de identificação.

A construção do imaginário individual se dá, essencialmente, por identificação (reconhecimento de si no outro), apropriação (desejo de ter o outro em si) e distorção (reelaboração do outro para si). O imaginário social estrutura-se principalmente por contágio: aceitação do modelo do outro (lógica tribal), disseminação (igualdade na diferença) e imitação (distinção do todo por difusão de uma parte). No imaginário há sempre desvio. (SILVA, 2003, p. 13).

A novidade, nesse caso, é que o indivíduo não é mais obrigado a integrar determinada comunidade, a motivação é pessoal, eletiva e espontânea. Os relacionamentos sociais originados em redes de computadores são desenvolvidos no ciberespaço, que pode ser compreendido como um lugar de circulação de informação, um espaço de comunicação, espaço virtual, que não existe em oposição ao real. O ciberespaço é o ambiente simbólico onde as comunidades virtuais se formam.

Nesse contexto, um outro fator que diferencia as comunidades virtuais das comunidades tradicionais é a ausência de um território, de uma localização geográfica. A existência de uma base territorial fixa não é mais necessária, embora o ciberespaço apresente-se como um espaço público fundamental para a existência de comunidades virtuais, um território simbólico. De acordo com Lemos (2002b), a noção de territorialidade não é 
física nas agregações eletrônicas. O constrangimento geográfico não é determinante para a formação comunitária, embora algumas comunidades não eletrônicas sejam também comunidades sem territorialidade física, como a própria comunidade acadêmica.

Ainda sobre a questão da existência de um território, Jones (1997) fala de virtual settlement ou estabelecimento virtual, que pode ser definido como um ciberlugar delineado simbolicamente em torno de um tópico de interesse e com uma proporção significativa de inter-relação interativa que caracteriza os grupos formados via CMC. Segundo Jones (1997), a consolidação de uma comunidade virtual, estruturada em um estabelecimento no ciberespaço, implica a presença das seguintes condições: um nível mínimo de interatividade; uma variedade de comunicadores; um número mínimo de membros fixos para dar suporte aos debates; e um espaço virtual público e comum onde ocorra uma parcela significativa de interação por meio da CMC.

Mais uma vez fica evidente que a aproximação entre as pessoas no ambiente virtual se dá por meio da existência de traços identitários comuns, pelo interesse em determinados assuntos, tanto que o participante escolhe qual grupo quer se inserir, podendo fazer parte de quantas comunidades desejar. Outro aspecto relevante para a formação de comunidades virtuais é o fator permanência temporal, de modo que os integrantes sintam-se realmente parte de um agrupamento de tipo comunitário (Lemos, 2002a), ou seja, possam criar um laço social permanente e contínuo.

\section{Aspectos metodológicos}

Realizou-se um estudo de caso baseado no método netnográfico visando identificar o grupo reunido na lista ABRH-Gestão como uma comunidade virtual. A netnografia é uma adaptação da etnografia para o ambiente virtual, usando técnicas e tradições da antropologia cultural (Kozinets, 1998; Sá, 2002). A pesquisa netnográfica foi desenvolvida por meio da prática da 
observação participante, que resulta na coleta de dados através da observação direta, de longa duração, junto ao grupo escolhido (Sá, 2002).

Kozinets (1998) acredita que a netnografia deva ser empregada no estudo de grupos de cibercultura "pura"5, grupos que não tem complemento na vida real, ou seja, que se manifestam exclusivamente via CMC. Segundo o autor, isso é indicado porque aqueles fenômenos são exclusivos de comunidades constituídas on-line e o uso de técnicas imersivas de netnografia permite ao pesquisador cobrir compreensivelmente o contexto social completo da "vida na tela".

Após um período de consulta das listas de discussão de caráter científico no sistema Yahoo! Brasil Grupos selecionou-se a lista ABRH-Gestão devido à temática abordada e a razões de tempo de manutenção e número de participantes; posteriormente, foi solicitada autorização do moderador para poder pesquisá-la.

Para a realização do trabalho de campo na Internet, houve a inserção do pesquisador no espaço virtual para investigar as práticas culturais do grupo que interagia de forma on-line, ou seja, usando uma linguagem específica baseada em códigos, símbolos e sinais, na escrita de palavras com letras maiúsculas ou minúsculas e com uma pontuação diferenciada (Kozinets, 1998). A coleta de dados consistiu no download das mensagens transmitidas na lista de discussão.

A análise do processo de interação social da lista ABRH-Gestão foi realizada através da observação participante durante um período de seis meses, de janeiro a junho de 2004. O material empírico de análise se concentrou no mês de abril em decorrência do nível significativo de debates apresentados. Por razões éticas, optou-se pela não identificação nominal dos

\footnotetext{
5 Embora a lista ABRH-Gestão esteja vincula a uma associação científica, tornando possível o encontro de alguns membros da lista e da associação na vida real, ela não é formada exclusivamente por sócios da ABRH. Dessa forma, considera-se a lista como um espaço virtual que reúne um grupo de cibercultura "pura".
} 
participantes da lista e, neste caso, as mensagens e seus respectivos autores foram identificados por números. A utilização da palavra mensagem pela sua forma abreviada (Msg.) é outra convenção adotada neste trabalho.

\section{A interação social na lista ABRH-Gestão}

A partir da análise netnográfica do processo de comunicação e de interação social da ABRH-Gestão, constata-se que a lista constitui uma comunidade virtual cujos integrantes são membros fixos e têm a possibilidade de se reunir para trocar informações sobre um tema central - recursos hídricos, interagindo e se inter-relacionando em um estabelecimento virtual (Jones, 1997), um espaço virtual público e comum em que o processo comunicacional desenvolve-se mediado por computador.

Dessa forma, a lista investigada detém todos os elementos necessários para ser definida como uma comunidade virtual, na medida em que permanece em atividade há mais de cinco anos e contava com a participação de cerca de 650 membros na época da realização deste estudo. Do total de inscritos, existe um número mínimo de pessoas que participa ativamente divulgando informações, cerca de $10 \%$, propondo questões e estimulando a participação dos demais. Os outros integrantes da lista participam lendo as mensagens e, eventualmente, concordando ou discordando das questões e argumentos apresentados, ou seja, a pauta está apoiada nas mensagens que recebem dos membros ativos.

Embora o número de participantes ativos seja relativamente baixo, é suficiente para manter dinâmica a interação social no interior da comunidade virtual, sendo que no período investigado foi registrada uma média de 91 mensagens transmitidas por mês. De um modo geral, a lista ABRH-Gestão pode ser considerada bem sucedida, apesar de nem todo dia haver trocas de mensagens, pois, às vezes, não surge nenhuma novidade ou debate. São enviadas em média três mensagens por dia, podendo ser trocadas até 14 
mensagens em um único dia em caso de discussão polêmica. $O$ fator de destaque é que a lista parece cumprir também a função de informar o que tem acontecido em termos de recursos hídricos no Brasil e em outros países.

O entendimento da lista como um ambiente voltado para a promoção de diálogos e debates é expressivo por parte dos membros, que a concebem enquanto um espaço de produção de sensações do vivido de forma conjunta (Lemos, 2002b). É o que se verifica, por exemplo, com as passagens: "Normalmente, tenho sido um observador silencioso das discussões que acontecem na rede. Entretanto, a proposta da lista é exatamente alavancar assuntos que despertem discussões em benefício da própria atividade de gestão.” (Msg. 35); “[...] gostaria de convidar o Sr. [...] para participar das discussões promovidas aqui nesse espaço democrático, quando teremos a oportunidade de aprender um pouco mais sobre a visão sociológica do processo de gestão de recursos hídricos [...]" (Msg. 48); e "A discussão e a troca de idéias é salutar e devemos saber ouvir e ter a oportunidade de falar a todos. Este é o lugar!!!” (Msg. 84). Assim, a ABRH-Gestão é um "lugar” tanto para promover o intercâmbio de informações e de experiências como para desencadear polêmicas e conflitos, marcando a complementaridade fundamental para a consolidação do conhecimento científico, como afirma Morin (1999).

O processo de comunicação na ABRH-Gestão está estruturado, majoritariamente, no envio de mensagens utilizando o correio eletrônico. Além desse recurso, os participantes costumam fazer o carregamento de arquivos de textos, mapas e fotos na página do grupo no Yahoo, uma vez que não é permitida a transmissão de material em anexo no corpo da mensagem, e ainda indicam links e sites de interesse na área como em: "FAÇA PARTE DO AMBIENTE TOTAL www.ambientetotal.pro.br [...]” (Msg. 5); “A documentação necessária à apresentação das propostas está disponível na Web, http://www.sg-guarani.org/particulares/ciudadania.htm” (Msg. 7); e 
"Link abaixo para maiores informações: http://www.repea.org.br/eanasbacias/smt/" (Msg. 26). Alguns participantes sugerem à consulta de sites pessoais como: “[...] ver seção HUMOR na minha página.” (Msg. 52).

A adoção da linguagem corrente no ambiente virtual também aparece no contexto da lista, porém, em menor proporção, como é o caso de palavras escritas em letras maiúsculas indicando gritos e ressaltando determinada colocação como: “[...] sem nenhum conhecimento das LEIS, DAS INSTITUIÇÕES, DA PRÁTICA DA VIDA, ETC....” (Msg. 52); “O tema praticamente não mudou pois continuamos buscando O DESAFIO DA PRÁTICA.” (Msg. 84) e na utilização de símbolos como “: )))).” (Msg. 82), que representam o sorriso e o bom humor do autor. Essa linguagem diferenciada é uma das características centrais da cibercultura e de relações sociais estabelecidas por meio de redes virtuais.

A lista tem um moderador que não desempenha um papel de censor e sua atuação, normalmente, está ligada à recepção de novos inscritos e à solução de problemas técnicos de funcionamento da ABRH-Gestão. A lista está aberta à associação de qualquer pessoa que solicitar sua inscrição e todo indivíduo cadastrado pode transmitir mensagens com o conteúdo que quiser, ou melhor, desde que esteja relacionado ao tema prioritário. $\mathrm{O}$ compromisso existente é com o grupo, com a manutenção da interação e do debate em torno de um tópico específico - recursos hídricos.

A interação social no interior da lista desenvolve-se de forma livre e não organizada, ou seja, acontece de acordo com a participação e o interesse de cada membro, como bem exemplifica a Msg. 75: "Vejo que a colocação da [autora da Msg. 67] volta, um pouco no tempo, a pergunta do Amigo [autor da Msg. 31]”. O conteúdo da Msg. 75 interage com as abordagens feitas anteriormente, mas que o autor considera importante retomar no momento atual da discussão. Nota-se que os membros promovem o diálogo e o debate 
conforme seus interesses e como acharem conveniente, não existindo uma ordem a seguir, uma pauta definida ou dada como encerrada.

A lista ABRH-Gestão configura-se em uma comunidade virtual (Rheingold, 1998; Lemos, 2002a, 2002b; Jones, 1997) de caráter científico por também reunir participantes das mais diversas áreas do conhecimento e que exercem diferentes profissões - advogados, biólogos, economistas, geógrafos, engenheiros, jornalistas, geólogos, sociólogos, entre outros. São pessoas que participam da lista porque imaginam ter afinidades e estão dispostas a compartilhar informações sobre recursos hídricos, afinal, não há laço social sem imaginação (Silva, 2003). A motivação é pessoal, subjetiva e eletiva, sendo o tema recursos hídricos o fator de atração que une a comunidade, é o elemento-chave identificador (Hall, 2001). Há uma identificação em torno do tópico discutido, prevalecendo um interesse em comum a ser partilhado, assim como um sentimento de pertencimento a uma comunidade.

É interessante notar ainda que no contexto de uma lista constituída por acadêmicos e cientistas o fator apresentação pessoal e profissional contribui, sobretudo, para facilitar a identificação por parte da comunidade, permitindo a formação de parcerias em projetos, na medida em que se conhece o tipo de estudo e o tema de interesse específico dos participantes, que pode gerar tanto redes de pesquisa quanto laços de amizade.

Os membros da ABRH-Gestão são responsáveis pelo processo dinâmico de interação, colaborando para que a lista continue em plena efervescência. $O$ fato de geralmente se inscreverem novos participantes na ABRH-Gestão também é marcante porque são pessoas de diferentes lugares e de diversas formações e interesses acadêmicos e/ou profissionais que se associam à lista de discussão para tomar conhecimento e se familiarizar com o tema recursos hídricos. Nesse sentido, a lista permite que cada indivíduo apresente suas dúvidas, necessidades e posicionamentos visando promover o debate e gerar 
reflexão sobre algum assunto em particular, como ilustra a Msg. 81: "Sou ecólogo e atualmente faço pós-graduação em geociências e meio ambiente. Não trabalho diretamente com gestão de recursos hídricos, e participo desta lista recentemente como curioso do assunto e aprendiz".

É possível verificar que prevalece um sentimento de valorização da lista entre os membros, que a consideram um espaço privilegiado por agregar pessoas favorecidas intelectualmente, como na Msg. 53: "Nem toda a comunidade científica possui o mesmo grau de conhecimento sobre a legislação de recursos hídricos que os participantes dessa lista possuem". Além disso, o depoimento de um representante da instituição ABRH de que a diretoria acompanha os debates que acontecem via lista, através da Msg. 78: "Os temas debatidos nessa lista estão sendo acompanhados pela Diretoria e serão debatidos na reunião a ocorrer no evento do Centro-Oeste”., reforça o papel da lista para os pesquisadores dedicados ao tema, já que os assuntos discutidos na ABRH-Gestão integram a pauta de eventos presenciais, ou seja, a vida na tela complementa a vida fora do ambiente virtual e vice-versa.

O caráter comunitário da lista, que supera a noção de uma simples agregação eletrônica (Lemos, 2002a), é percebido quando se veicula ao longo de meses a mensagem: "Nossa homenagem ao colega [...], idealizador e primeiro moderador dessa lista.", homenageando o primeiro moderador pela proximidade da data de sua morte. Nesse momento, a comunidade virtual e imaginada (Anderson, 1989) lamenta junto, coletivamente, a perda de uma pessoa importante para o grupo, apesar de nem todos os participantes o terem conhecido. Isso é uma prova do compromisso e do respeito estabelecido pela comunidade da ABRH-Gestão, mesmo estando consciente que o desligamento da lista pode ser feito a qualquer hora, sem causar constrangimento, pois cada participante decidiu fazer parte daquele grupo por vontade própria, tratandose de uma atitude espontânea. 
A presença do sentimento de pertencimento a um agrupamento de caráter comunitário é verificada, inclusive, pela forma de tratamento usada entre os participantes, seja na saudação inicial do grupo como: "colegas da lista ABRH-Gestão" (Msg. 16); "Caros colegas da lista” (Msg. 29); "Prezados Companheiros da Lista” (Msg. 45); “Car@s” (Msg. 63); "Prezados listeiros” (Msg. 67) ou em frases de despedida como é o caso de: "Muita paz, saúde e luz!” (Msg. 4); “Com a palavra os co-listeiros” (Msg. 31); "Um fraternal abraço" (Msg. 38); "Saudações hídricas” (Msg. 46); "saudações fluviológicas” (Msg. 52); e “Abraços e boa leitura” (Msg. 82). Estas expressões são utilizadas exclusivamente por membros de grupos formados virtualmente, que se vêem como integrantes de uma comunidade, pessoas que se reúnem, encontram-se e convivem socialmente por meio da rede, representando a chamada sociedade em rede, na concepção de Castells (1999, 2003).

Os participantes da lista são de diversas localizações geográficas, representando o país de Norte a Sul, assim como há também pessoas de outros países, em menor quantidade, mas que convivem e se relacionam em uma comunidade virtual imaginária, já que muitos não se conhecem pessoalmente, incluindo o moderador, que revela não conhecer a maioria dos inscritos. Sobre esse ponto de vista, verifica-se que as pessoas reunidas na ABRH-Gestão formam uma comunidade virtual científica ao se relacionar e interagir mutuamente, como propõe Primo (1998).

\section{Considerações finais}

A investigação da lista ABRH-Gestão permite identificar o processo dinâmico de comunicação e de interação social fomentado pelos participantes do grupo, sendo a comunicação mantida predominantemente a partir da troca de mensagens textuais usando o correio eletrônico. A lista de discussão apresenta-se como um espaço virtual público e comum voltado para o amplo 
debate sobre a área de recursos hídricos enfatizando a realidade nacional, embora aborde também assuntos de interesse mundial.

Com base neste aspecto, verifica-se que os estudantes, professores, pesquisadores e cientistas, que atuam nas mais diversas áreas do conhecimento e que estão ligados pela identificação (Hall, 2001) em torno de um tópico comum, uma afinidade - recursos hídricos, formam uma comunidade virtual (Rheingold, 1998; Lemos, 2002a, 2002b) científica estruturada em um virtual settlement ou estabelecimento virtual (Jones, 1997). Assim, a lista é concebida enquanto um espaço virtual de discussões públicas que reúne um número considerável de participantes fixos, sendo que dentre estes prevalece uma quantidade mínima de integrantes responsáveis pela geração de diálogos e debates através da inter-relação e da interatividade mútua via CMC (Primo, 1998).

De acordo com a origem das listas de discussão, destinadas a promover a comunicação coletiva baseada na cooperação dos participantes e no intercâmbio de conhecimentos, a ABRH-Gestão também corresponde a essa função (Fuks; Gerosa; Pimentel, 2003). Nota-se, portanto, que a interação social no interior da lista é fundamental para a construção de novos saberes, por meio da expressão de opiniões e sugestões, muitas das vezes divergentes. A lista ainda tem um papel relevante como espaço de comunicação para o grupo reunido, pois reforça a pauta de discussão em encontros face a face, complementando os acontecimentos da vida na tela. Desse ponto de vista, considera-se a lista de discussão ABRH-Gestão um ciberlugar de intercâmbio coletivo de informações, de experiências e vivências, aberto a pessoas motivadas a compartilhar saberes, conhecimentos e preocupações em comum, mantendo um laço social imaginado (Silva, 2003).

A comunidade estruturada via lista de discussão é formada por pessoas de diferentes localidades geográficas, abrangendo todas as regiões do Brasil e com participantes de outros países. Nesse sentido, o ciberespaço ignora, 
definitivamente, aspectos de tempo e de distância espacial como limitadores do convívio social, auxiliando na formação de comunidades virtuais imaginadas (Anderson, 1989). Ademais, a constituição de comunidades virtuais configura-se em uma estratégia do indivíduo que se relaciona no ciberespaço, que vive em uma sociedade em rede, de se fazer reconhecer diante dos outros, sendo à busca de mecanismos de identificação uma prática constante na história da humanidade.

O nível elevado de interação, assim como o uso de outros recursos de comunicação on-line, como consulta a sites e a utilização da própria linguagem característica do ambiente virtual, ajudam a indicar a consolidação de uma cibercultura científica no Brasil. Por outro lado, fazendo um paralelo com o estudo de Pinheiro (2003) - que apontou as listas de discussão como a segunda ferramenta mais usada por pesquisadores brasileiros, verifica-se com esta análise da ABRH-Gestão que o contato via listas contribui também para a formação de comunidades virtuais sobre temas acadêmicos e científicos.

Vale ressaltar, ainda, que a forma de apropriação de qualquer tecnologia está associada diretamente à competência intelectual e ao interesse pessoal do internauta para poder se beneficiar ou não. Com isso, afasta-se qualquer visão de endeusamento da tecnologia que sozinha não é capaz de manter em atividade uma lista de discussão durante cinco anos e em plena efervescência (Wolton, 2003), pois seu sucesso ou fracasso depende da participação direta dos integrantes da comunidade virtual. 


\section{Referências}

ANDERSON, Benedict. Nação e Consciência Nacional. São Paulo: Ática, 1989. $191 \mathrm{p}$.

ASSOCIAÇÃO BRASILEIRA DE RECURSOS HÍDRICOS. [2004]. Disponível em: <http://www.abrh.org.br>. Acesso em: 10 jul. 2004.

CASTELLS, Manuel. A Era da Informação: economia, sociedade e cultura. São Paulo: Paz e Terra, 1999. 617 p. (A Sociedade em Rede, v. 1). Internet e sociedade em rede. In: MORAES, Dênis de (Org.). Por uma outra Globalização: mídia, mundialização cultural e poder. Rio de Janeiro: Record, 2003. p. 255-287.

COSTA, Sely M. S.. Mudanças no Processo de Comunicação Científica: o impacto do uso das novas tecnologias. In: MUELLER, Suzana Pinheiro Machado (Org.).; PASSOS, Edilenice Jovelina Lima (Org.). Comunicação

Científica. Brasília: Departamento de Ciência da Informação Universidade de Brasília, 200o. p. 85-105.

FUKS, H.; GEROSA, M.A.; PIMENTEL, M. G.. Projeto de Comunicação em Groupware: desenvolvimento, interface e utilização. In: CONGRESSO DA SOCIEDADE BRASILEIRA DE COMPUTAÇÃO, 23., 2003, Campinas.

Anais... Campinas: UNICAMP, 2003. Disponível em:

$<$ http://groupware.les.inf.pucrio.br/groupware/publicacoes/HTML/JAI2003_cap7.htm>. Acesso em: 30 abr. 2004.

HALL, Stuart. A Identidade Cultural na Pós-modernidade. Rio de Janeiro: DP\&A, 2001. 102 p.

JONES, Quentin. Virtual-Communities, Virtual Settlements \& CyberArchaeology: a theoretical outline. [1997]. Disponível em:

<http://www.ascusc.org/jcmc/vol3/issue3/jones.html>. Acesso em: 10 ago. 2004. 
KOZINETS, Robert V.. On Netnography: initial reflections on consumer research investigations of cyberculture. [1998]. Disponível em: <http://www.kellogg.nwu.edu/faculty/Kozinets/htm/Research/printouts/koz inetsOnNetnography.pdf>. Acesso em: 20 ago. 2003.

LEMOS, André. Agregações Eletrônicas ou Comunidades Virtuais? Análise das listas Facom e Cibercultura. [2002a]. Disponível em: <http://www.facom.ufba.br/ciberpesquisa/agregacao.htm>. Acesso em: 8 fev. 2004.

\section{Cibercultura, Tecnologia e Vida Social na Cultura}

Contemporânea. Porto Alegre: Sulina, 2002b. 320 p.

MEADOWS, Arthur Jack. A Comunicação Científica. Brasília: Briquet de Lemos, 1999. 268 p.

Avaliando o Desenvolvimento da Comunicação Eletrônica. In: MUELLER, Suzana Pinheiro Machado (Org.).; PASSOS, Edilenice Jovelina Lima (Org.). Comunicação Científica. Brasília: Departamento de Ciência da Informação Universidade de Brasília, 2000. p. 23-34.

MORIN, Edgar. O Método 3: o conhecimento do conhecimento. Porto Alegre: Sulina, 1999. 288 p.

PINHEIRO, Lena Vania Ribeiro. Comunidades Científicas e Infra-estrutura Tecnológica no Brasil para Uso de Recursos Eletrônicos de Comunicação e Informação na Pesquisa. Ciência da Informação, Brasília, v.32, n.3, p.6273, set./dez. 2003. Disponível em:

<http://www.ibict.br/cienciadainformacao/include/getdoc.php?id=168\&artic le $=46 \&$ mode $=$ pdf $>$. Acesso em: 10 abr. 2004.

PRIMO, Alex Fernando Teixeira. Interação Mútua e Interação Reativa: uma proposta de estudo. In: CONGRESSO DA SOCIEDADE BRASILEIRA DE ESTUDOS INTERDISCIPLINARES EM COMUNICAÇÃO, 21., 1998, Recife. Anais... Recife: UFPE, 1998. Disponível em: 
<http://usr.psico.ufrgs.br/ aprimo/pb/espiralpb.htm>. Acesso em: 10 jul. 2003.

RHEINGOLD, Howard. The Virtual Community. [1998]. Disponível em: <http://www.rheingold.com/vc/book/>. Acesso em: 05 jul. 2003.

RUSSELL, Jane M.. Tecnologias Eletrônicas de Comunicação: bônus ou ônus para os cientistas dos países em desenvolvimento?. In: MUELLER, Suzana Pinheiro Machado (Org.).; PASSOS, Edilenice Jovelina Lima (Org.).

Comunicação Científica. Brasília: Departamento de Ciência da Informação Universidade de Brasília, 2000. p. 35-49.

SÁ, Simone Pereira de. Netnografias em Redes Digitais. In: PRADO, José Luiz Aidar (Org.). Crítica das Práticas Midiáticas: da sociedade de massa às ciberculturas. São Paulo: Hacker, 2002. p. 147-164.

SILVA, Juremir Machado da. As Tecnologias do Imaginário. Porto Alegre: Sulina, 2003. $111 \mathrm{p}$.

SOUZA, Maria da Paixão Neres de. Efeito das tecnologias da informação na comunicação de pesquisadores da Embrapa. Ciência da Informação, Brasília, v.32, n.1, p.135-143, jan./abr. 2003. Disponível em:

$<$ http://www.ibict.br/cienciadainformacao/include/getdoc.php?id=454\&artic le $=171 \&$ mode $=p d f>$. Acesso em: $10 \mathrm{abr} .2004$.

WOLTON, Dominique. Internet, e depois? Uma teoria crítica das novas mídias. Porto Alegre: Sulina, 2003. 232 p. 